\title{
Exploring Renewable Energy Resources Using Remote Sensing and GIS-A Review
}

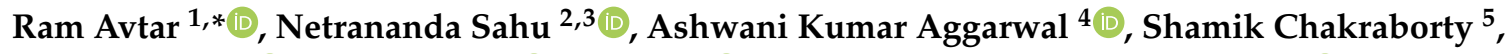 \\ Ali Kharrazi ${ }^{6,7}$, Ali P. Yunus ${ }^{8}\left(\mathbb{D}\right.$, Jie Dou ${ }^{9}\left(\mathbb{D}\right.$ and Tonni Agustiono Kurniawan ${ }^{10} \mathbb{D}$ \\ 1 Faculty of Environment Earth Science, Hokkaido University, Sapporo 060-0810, Japan \\ 2 Department of Geography, Delhi School of Economics, University of Delhi, New Delhi 110007, India \\ Disaster Prevention Research Institute, Kyoto University, Kyoto 611-0011, Japan \\ 4 Electrical and Instrumentation Engineering Department, Sant Longowal Institute of Engineering and \\ Technology, Longowal, Punjab 148106, India \\ 5 Faculty of Sustainability Studies, Hosei University, 2-17-2 Fujimi Chiyoda-ku, Tokyo 102-8160, Japan \\ 6 CMCC Foundation - Euro-Mediterranean Center on Climate Change and Ca' Foscari University of Venice, \\ 30175 Venice, Italy \\ 7 Advanced Systems Analysis Group, International Institute for Applied Systems Analysis, Schlossplatz 1, \\ A-2361 Laxenburg, Austria \\ 8 State Key Laboratory of Geo-hazard Prevention and Geo-environment Protection, \\ Chengdu University of Technology, Chengdu 610059, China \\ 9 Department of Civil and Environmental Engineering, Nagaoka University of Technology, \\ Nagaoka 940-2188, Japan \\ 10 Key Laboratory of the Coastal and Wetland Ecosystems (Xiamen University), Ministry of Education, College \\ of the Environment and Ecology, Xiamen University, Xiamen 361102, China \\ * Correspondence: ram@ees.hokudai.ac.jp; Tel.: +81-011-706-2261
}

Received: 30 June 2019; Accepted: 15 August 2019; Published: 19 August 2019

\begin{abstract}
Renewable energy has received noteworthy attention during the last few decades. This is partly due to the fact that fossil fuels are depleting and the need for energy is soaring because of the growing population of the world. This paper attempts to provide an idea of what is being done by researchers in remote sensing and geographical information system (GIS) field for exploring the renewable energy resources in order to get to a more sustainable future. Several studies related to renewable energy resources viz. geothermal energy, wind energy, hydropower, biomass, and solar energy, have been considered in this paper. The focus of this review paper is on exploring how remote sensing and GIS-based techniques have been beneficial in exploring optimal locations for renewable energy resources. Several case studies from different parts of the world which use such techniques in exploring renewable energy resource sites of different kinds have also been included in this paper. Though each of the remote sensing and GIS techniques used for exploration of renewable energy resources seems to efficiently sell itself in being the most effective among others, it is important to keep in mind that in actuality, a combination of different techniques is more efficient for the task. Throughout the paper, many issues relating to the use of remote sensing and GIS for renewable energy are examined from both current and future perspectives and potential solutions are suggested. The authors believe that the conclusions and recommendations drawn from the case studies and the literature reviewed in the present study will be valuable to renewable energy scientists and policymakers.
\end{abstract}

Keywords: geothermal energy; wind energy; biomass; hydropower; solar energy; renewable energy resources; fossil fuel 


\section{Introduction}

Non-renewable energy resources based on fossil fuel such as coal, oil, natural gas, and fuelwood are extensively used for the generation of electricity, transportation, heating homes, and in manufacturing industries among others. However, non-renewable energy resources are depleting because of increased demand for energy due to the growing population [1-3]. With growing recognition and scientific consensus on the threat of climate change in the global community, the need to divest from fossil fuels and transition towards renewables has been brought under the spotlight in recent years [4]. It is therefore necessary to find alternative energy sources, as the need for energy will always be there. The share of renewable energy resources has increased considerably in the generation of electricity, heating systems, and transportation in urban areas [5]. This paper focuses on five types of renewable energy resources viz. geothermal, wind, biomass, hydropower and solar (Figure 1).

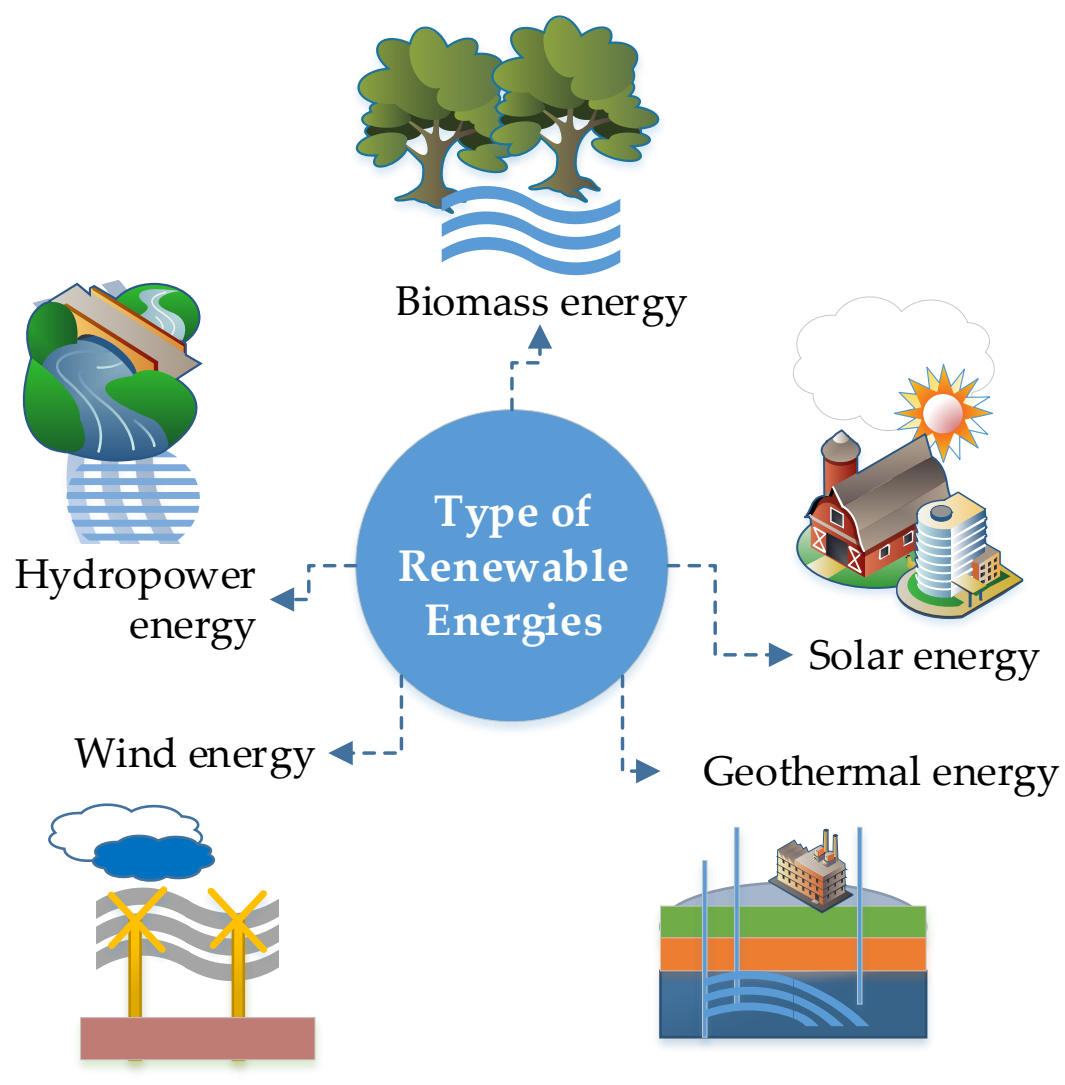

Figure 1. The types of renewable energy resources discussed in this paper: biomass, solar, geothermal, wind, and hydropower.

Geothermal energy is seen as an environmentally feasible option. According to the Intergovernmental Panel on Climate Change (IPCC) special report on renewable energy sources, climate change is not likely to have any major adverse impacts on the reliability of geothermal energy, but the widespread utilization of geothermal energy could play a significant role in substantially reducing greenhouse gas emissions [6]. Additionally, modern reservoir management technologies coupled with the natural continuous replenishment of heat from earth processes ensure that such geothermal systems can be used sustainably. Geothermal energy is physically generated from the heat that primarily comes from the decay of naturally occurring radioactive isotopes in the earth. This internal heat combustion is estimated to generate total thermal energy to a depth of $10 \mathrm{~km}$ of $1.3 \times 10^{27} \mathrm{~J}$. This is equivalent to burning $3.0 \times 10^{17}$ barrels of oil [7]. Considering that the consumption of total global energy is equivalent to approximately 100 million barrels of oil per day, geothermal energy could theoretically supply energy requirements for six million years [8]. Geothermal resources 
can be broadly classified into three categories: hydrothermal or convective systems, conductive systems, and deep aquifers. Hydrothermal (convective) systems may either be vapor-dominated or water-dominated [9]. Characteristic surface manifestations include hot springs, fumaroles, and chemically-altered rocks. Sometimes though, there are no such surface manifestations. Meanwhile, conductive systems include hot rock and magmatic resources, and deep aquifers contain moving fluids in porous media at depths more than $3 \mathrm{~km}$, but without a local magmatic heat source. Electric power can be generated with steam or using a secondary hydrocarbon vapor to drive turbine-generators set to produce electrons. At present, geothermal energy accounts for about $0.4 \%$ of the world's global power generation, with a growth rate of $5 \%$. In contrast, solar energy currently provides less than $0.2 \%$ of the global power generation, but it is having a high growth rate of about 25-30\% [10]. Presently, the total installed capacity for geothermal resources worldwide is 10,898 MW, corresponding to approximately 67,246 GWh of electricity [6].

Wind energy, another alternative to fossil fuels, is the plentiful, renewable and clean source. Wind power converts wind energy into electrical energy. Small onshore wind farms provide electricity to isolated locations. The statistics show that wind energy sources are amongst the world's fastest developing energy sources. Since 2000-2006 the wind energy sources has quadrupled, with many new projects in China, United States, Denmark among other countries [11,12]. The potential of a wind energy project significantly depends on the location of the project. A proper assessment before investment helps in predicting the outcome of the project and reduces the uncertainty [13]. The main characters of the success of a wind energy project lie on the factors such as the wind power density, the elevation above mean sea level, the topography of the terrain, the connectivity through the road network, the proximity to the electric grid, and the distance from conserved areas [14]. Based on the location, wind farms are distinguished into two categories viz. Onshore and Offshore [15]. The wind farms located on land are generally known as the onshore farms. For the onshore wind farm projects, the topography of the land and roughness of the surface is taken into consideration. The proximity to the transmission and road network is also considered. For onshore wind farms, mainly satellite images are analyzed to check the feasibility of the locations and elevations [16]. The satellite imaging sets guidelines for further decision making in case of the wind farm projects.

Along with satellite images, the Light Detection And Ranging (LiDAR), SOnic Detection And Ranging (SODAR), and Synthetic Aperture Radar (SAR) are also extensively used in wind farms. The use of remote sensing helps in optimizing the process of installing met mast based sensors [17]. The wind farms located in lake, river, sea are known as offshore wind farms. In the offshore wind farms, the resources need to be qualified prior to financing farm. In offshore wind energy, remote sensing can be used in three different ways: Ground-based, airborne and satellite-borne. Ground-based techniques are efficient in the case when large wind turbines are to be installed and meteorological masts do not enable observations across the rotor plane [18]. It is commonly used at heights approximately $100 \mathrm{~m}$ to $200 \mathrm{~m}$ above the ground level [19].

Perennial biomass crops and fast-growing non-food crops have the potential to offer sustainable bioenergy production [20]. Biomass refers to the biological material from living organisms or plants. It is one of the most commonly used energy sources in less industrialized and less developed countries [21]. Biomass is the most developed renewable energy source providing $35 \%$ and $3 \%$ of the primary energy needs of developing and developed countries respectively [22]. Biomass can be used as an energy source either combusting directly to produce heat or indirectly after converting to various form of biofuel [23]. Biomass from forest residues such as dead trees, branches, and stems can be converted to other usable forms of energy like methane gas or transportation fuels like ethanol and biodiesel. The usage of biomass varies with region. The wood residues are commonly used in the United States, agricultural waste is commonly used in Mauritius and Southeast Asia and animal husbandry residue is common in the United Kingdom [24]. Forests play a vital role in the carbon cycle of the globe and are also the cheapest and easily available renewable energy source for the human being as compare to the solar, but the quantification is required to identify the available capacity in planning biomass 
power plant project. Remote sensing data provide the capability of biomass estimation [25]. Ground or conventional assessment of biomass is not sufficient to cover the large area with limitation of budget and time and using remote sensing as a tool to estimate the forest biomass has been found efficient. Remote sensing is used as an important tool to examine the dispersed geographic distribution of economically exploited biomass potential, evaluation of biomass supply and its characteristics as well as estimating the approximate cost of transportation to the power plant units [23]. Though the biomass is distributed over extensive areas, transportation cost is a critical factor in planning new biomass power plants [26]. The amount of usable biomass within an area can be calculated and optimal sites were identified by reducing the transportation cost by means of remote sensing techniques. By removing forest debris, renewable energy from forest biomass can improve forest health and dramatically reduce the risk of forest fires [27]. Biomass power plant units reduce the open burns of agricultural waste and forest slash. At the same time, biomass power plant units continue to balance the use of fossil fuels [28]. In this way, Biomass power greatly improves air quality and being a natural solution to meeting higher renewable energy standards [29].

Among all renewable energy sources, hydropower seems to be more reliable and cleaner. The most important feature of hydropower is less emission of greenhouse gases [30]. The basis of generating hydropower is converting the kinetic energy of water into electricity using turbines. However, selecting a site for a hydropower plant is complicated and has to deal with sensitive issues such as degradation of riverine ecosystems including biodiversity, therefore it needs more careful planning. Land use pattern, elevation, catchment area, soil classification, stream network, flow characteristics, and biodiversity attributes are some of the important studies that need to be carried out before the site selection [31]. Remote sensing and GIS are useful tools available for this kind of studies and various methods are available therefore critical analysis of literature is required. The conventional way of assessing hydropower potential site is inaccurate and has several consequences [32]. Some of the disadvantages in the conventional method are an underestimation, observation at a particular location might miss a better location and covering a large spatial area is expensive and time-consuming [33]. These issues can be vastly reduced by advanced computational tools like remote sensing and GIS. Moreover, GIS and remote sensing provide a true picture of existing terrain, complex hydrological phenomena and variable climate which are necessary for assessment of potential hydropower plant. Temporal stimulation along with spatial modeling are the biggest advantages of these tools [34].

Another option for renewable energy is to look into what the sun can provide in terms of energy. Indeed, the sun is considered as a vital source of renewable energy [35]. According to the United States Department of Energy, solar technology was developed as far back as the 7th century. It started as the heat being concentrated with mirrors and glass in order to light fires. Solar energy also has multiple advantages, such as the fact that it is obviously abundant and free. Though the installation has a cost, technology improvements are making it more cost-effective. Solar energy is a good option for remote locations where mainstream facilities are hard to get or install [36]. Furthermore, the creation of this energy requires little maintenance, and its production is silent. Only 2000 millionths of sun radiation are received on the earth, also known as visible and infrared radiations. However, it is enough to generate a lot of energy. According to Dr. Gerhard Knies from DESERTEC Foundation, in only six hours, all the deserts combined from our planet receives more energy from the sun than what humankind can consume within a year [37]. Furthermore, according to the International Energy Agency, the sun might be the biggest source of electricity by the year 2050, followed by fossil fuels, wind energy, hydropower and nuclear energy $[38,39]$. The amounts of short-wave radiant energy are emitted by the sun's disc and are scattered diffusively by the atmosphere and the clouds. The radiations can be divided into two categories; the direct radiation, which is responsible for creating shadows, and the diffuse radiations, responsible for producing a skylight. In order to fully use that renewable energy, it is important to first assess the availability of the resource spatially as well as temporally. Indeed, the sun's irradiance (intensity of sun's radiation) is roughly constant, which means that the only obstacles from capturing the energy come from clouds, shadows or aerosols (particles in the atmosphere). It shows that targeting 
a specific area where those factors are not of big concern is essential. However, how is it done? Thanks to today's technologies, it is possible to locate optimal places where it is available and where it is needed. This is where remote sensing and GIS come in place [40]. There is a big number of papers that show the effectiveness of this technology. The papers also show multiple methods used for the matter.

The objective of this paper is to present a comprehensive review of potential applications of remote sensing and GIS techniques for exploring five-main renewable energy related to water-soil-air resources. The finding can be instructive to the policy-makers to develop subsidies with the alternative decisions for available renewable energy resources. First, a methodology to search for relevant literature is presented. Second, a brief overview of the status of conventional methods used and the role of remote sensing and GIS techniques in renewable energy resources have been discussed. Third, several case studies of remote sensing and GIS techniques used in the exploration of renewable energy resources have been presented. Lastly, a summary and discussion on the various research methods used by researchers in exploring renewable energy resources using remote sensing and GIS techniques have been provided. The conclusion drawn from the study is presented at the end of this paper.

\section{Methodology}

The flowchart of the review study was shown in Figure 2. The case studies were identified based on the potential application of remote sensing in exploring and estimation of renewable energy related to wind, solar, hydropower, geothermal and biomass resources in the context of economic and social dimensions. We noted that the literature review, the latest work in the Asian region and other countries were obtained. The primary and secondary sources of data were used for this review. A database of published articles on the role of remote sensing and GIS techniques in the exploration of renewable energy resource sites was established using the web of science and Google Scholar because of the useful multidisciplinary database. Group discussion was conducted two times among scientists and stakeholders, the first time in deciding types of renewable energy and selecting case studies. Keywords such as "remote sensing in renewable energy", "renewable energy resources exploration", "GIS in renewable energy", "renewable energy resources" and "remote sensing" and "GIS" were chosen as search terms. The results obtained using these keywords were 3, 9, 23 and 1230 respectively. A lot of attention has also been given on the policy related research articles to identify the application of remote sensing and GIS in renewable energy management. To obtain a large range of relevant articles, we have added papers relating to resource management, energy production, and energy reports. After adding these papers, we have omitted irrelevant papers from the collection by going through the abstracts, discussion, and conclusions. To understand the main focus of papers in the field of applications and the role of remote sensing and GIS techniques in renewable energy resources, the selected set of papers were read judiciously several times. After that, the main findings of each of the paper were noted down along with their research scale, adopted methods, the illustration of concepts and their limitations.

A statistical analysis of outlier papers was carried out for rejection of 59 papers downloaded using the keywords. Figure 3 gives a pictorial representation for analysis of reasons for rejection of outlier papers. 


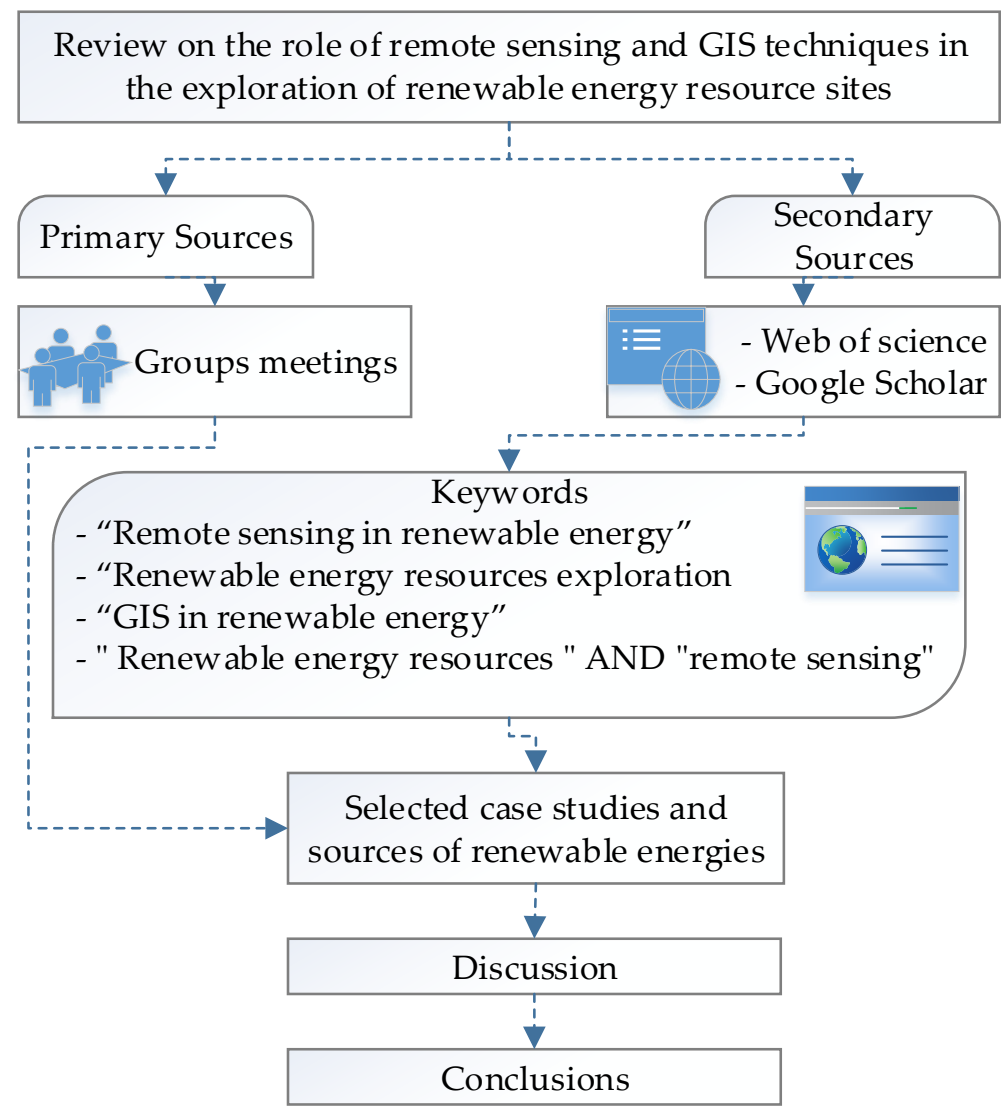

Figure 2. Flowchart of review on renewable energy based on remote sensing.

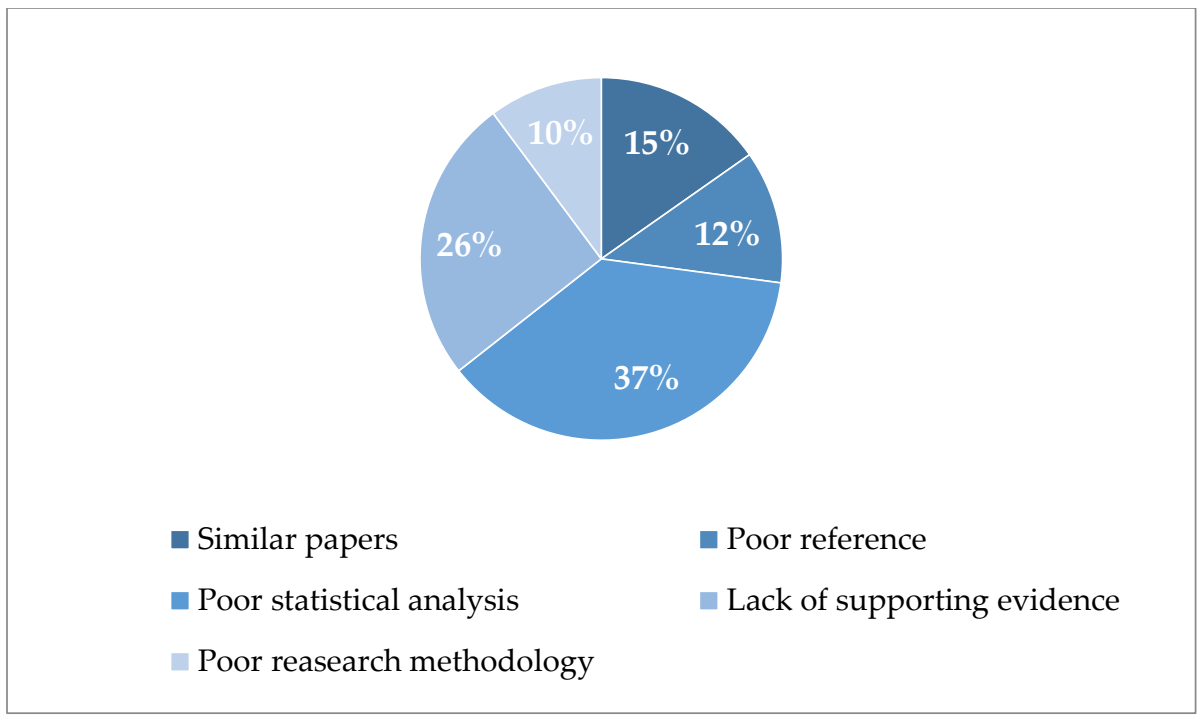

Figure 3. Analysis of reasons for rejection of outlier papers.

\section{Conventional Methods Used for the Development of Renewable Energy Resources}

There are various automatic methods like segmentation and classification that are used in the field of renewable energy resources. From a resource perspective, the phases of geothermal project development can be divided into (i) project definition and aka reconnaissance evaluation, (ii) exploration, (iii) exploratory drilling (iv) resource analysis (v) field development, (vi) steam production and (vii) abandonment [41]. While a detailed description of each phase is not in the scope 
of the current paper, it can be inferred that remote sensing has potential applicability in several of the preceding stages. The most evident potential application of remote sensing and GIS to geothermal power development is in the initial exploratory and reconnaissance phase [42]. Traditionally, this phase involves the collection of secondary data from previous studies, as well as documentation of indigenous use of geothermal resources [43]. There is an emphasis on the mapping of volcanic activity and thermal manifestations on the ground surface, such as hot springs and steam jets. Several in-situ methods have been previously used in this stage of geothermal characterization, especially when the project moves on to a more detailed feasibility study stage [44] provides a comprehensive overview of conventional methods for geothermal energy development, as well as trends in geothermal technology utilization in the early part of the 21st century. More recently, an updated review of geophysical methods has been given by some researchers for geothermal exploration [45]. Some of the typical reconnaissance methods include surveys on hydrogeological, geochemical, and geophysical techniques such as seismic, gravity, magnetic, electrical resistivity, electromagnetic, and thermal measurement surveys [46]. Hydrogeological surveys are used to have a better understanding of the water circulation system, by considering flow paths relating surface manifestations and subsurface lithological features such as faults and fractures. Geochemical surveys collect and analyze water, gas, and steam samples to develop suitable geothermometers based on fluid chemistry for estimating deep reservoir temperatures. Seismic surveys are used to find the composition and properties of subsurface rock formations, as well as the site of active faults which can be conduits of hot fluids to the surface. Gravity surveys, though not by themselves necessarily indicative of geothermal resources, are useful in gathering data on rock type and depth distribution, as well as geometric characteristics. Magnetic surveys provide similar information on subsurface lithology and are used on the principle that magnetite in near-surface rocks is destroyed by hydrothermal processes. Electrical resistivity surveys measure the voltage differences between hot and cold rock regions, as a consequence of rock porosity as well as salinity of interstitial fluids in the shallow subsurface. Electromagnetic surveys are used to determine subsurface properties at depths ranging from $300 \mathrm{~m}$ to several kilometers. Finally, thermal measurement surveys provide information on subsurface temperature variation and heat flow, as well as the intensity and location of thermal anomalies. Numerical reservoir modeling can be used to integrate the data from these methods to generate a more detailed understanding of the subsurface reservoir behavior, to identify optimal drilling locations, and to forecast future system conditions based on environmental change and management scenarios.

\section{Role of Remote Sensing and GIS in Exploring Renewable Energy Resources}

The main objective of surveys discussed in Section 3 is to generate a detailed model of the subsurface, in order to understand the physical processes as well as the economic feasibility of developing a geothermal plant. Yet, even in these long-standing methods, uncertainties associated with heterogeneity and anisotropy remains. Figure 4 shows, that remote sensing and GIS together with ground-based monitoring can obtain information about the surface of the earth, contributing significantly to renewable energy resource development This section will demonstrate that there is, in fact, ample scope for remote sensing to complement the aforementioned in-situ methods particularly in the exploratory phase of site selection (see Table 1). Categorically speaking, remotely-sensed data may serve as direct or indirect evidence of geothermal activity. Direct evidence refers to the surface information that can be immediately linked to geothermal activity, based on well-understood physical processes. Meanwhile, indirect evidence requires additional interpretation, and often, additional data to prove that this information is related to geothermal activity. 


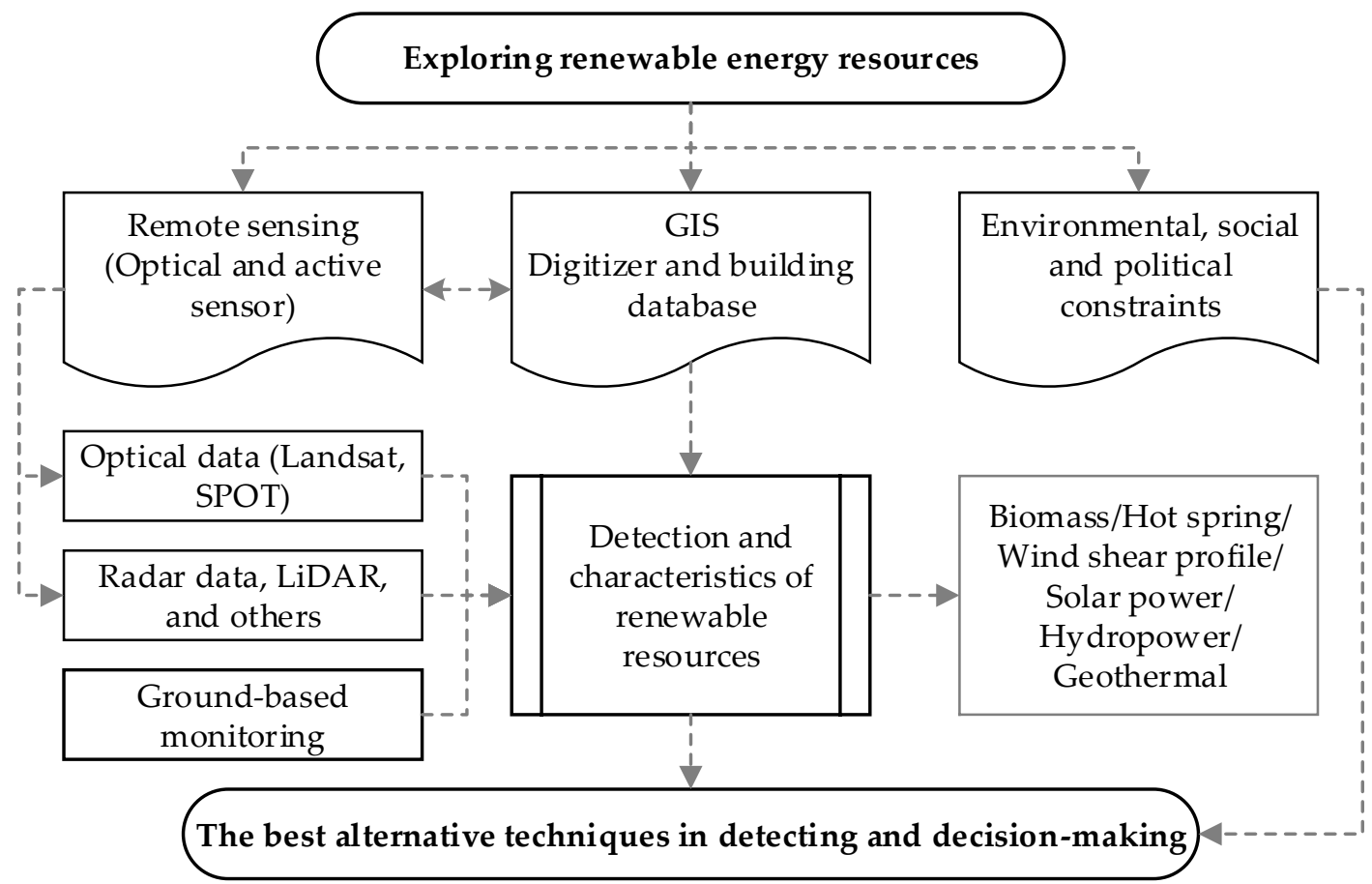

Figure 4. Flowchart of exploring renewable energy resources by combination of remote sensing and GIS.

Table 1. Geothermal energy exploitation and mapping.

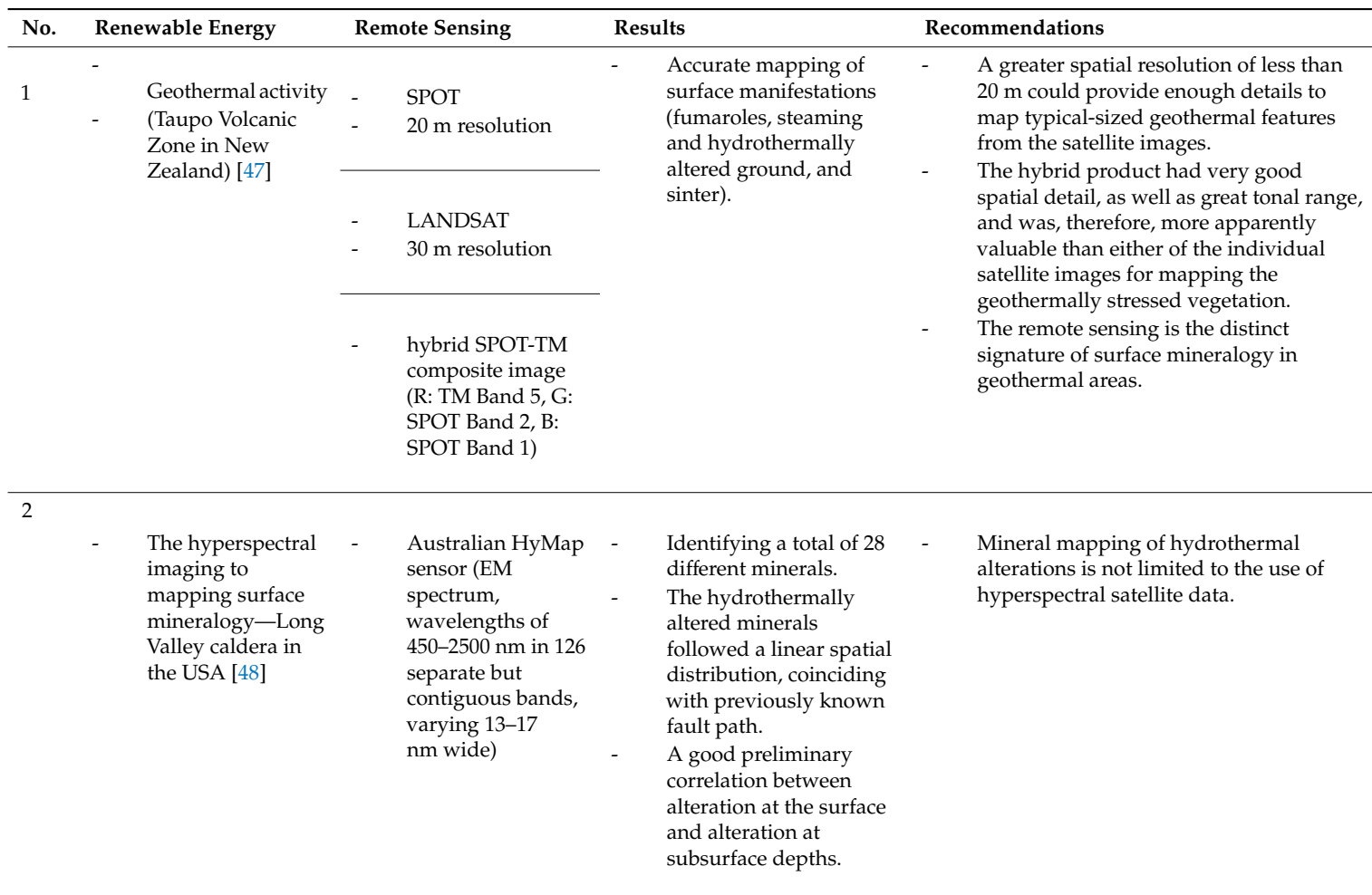


Table 1. Cont.

\begin{tabular}{|c|c|c|c|c|}
\hline No. & Renewable Energy & Remote Sensing & Results & Recommendations \\
\hline & $\begin{array}{l}\text { The hydrothermal } \\
\text { altered mineral } \\
\text { deposits around } \\
\text { the Kuju Volcano } \\
\text { in Japan [49] }\end{array}$ & Landsat 7 ETM+ & $\begin{array}{l}\text { The selected band } 7 \text { as } \\
\text { the modeled band, and } \\
\text { all six visible bands and } \\
\text { the short-wave infrared } \\
\text { band as predictors to } \\
\text { map the distribution of } \\
\text { clay alterations. } \\
\text { The identification } \\
\text { specific of hydrothermal } \\
\text { altered minerals based } \\
\text { on the library of } \\
\text { minerals known spectral } \\
\text { reflectance published by } \\
\text { the USGS. }\end{array}$ & $\begin{array}{l}\text { The multispectral satellite images can be } \\
\text { efficiently utilized for the mapping of } \\
\text { hydrothermal altered minerals by using } \\
\text { the various appropriate } \\
\text { processing techniques. }\end{array}$ \\
\hline 4 & $\begin{array}{l}\text { The mineral } \\
\text { mapping for } \\
\text { geothermal } \\
\text { exploration [49] }\end{array}$ & & $\begin{array}{l}\text { ASTER could only map } \\
\text { general mineral groups } \\
\text { rather than } \\
\text { specific minerals. } \\
\text { The airborne sensors } \\
\text { SEBASS and MAGI } \\
\text { allowed the detection } \\
\text { and quantification of } \\
\text { specific surface minerals } \\
\text { at geothermal fields. }\end{array}$ & $\begin{array}{l}\text { The space-borne sensors should be } \\
\text { launched with at least } 30 \text { spectral TIR } \\
\text { channels to allow for mapping of specific } \\
\text { minerals and surface units for } \\
\text { geothermal applications. }\end{array}$ \\
\hline 5 & $\begin{array}{l}\text { The mineral } \\
\text { mapping for } \\
\text { geothermal } \\
\text { exploration Salton } \\
\text { Sea, CA [50] }\end{array}$ & $\begin{array}{l}\text { - } \quad \text { SEBASS, ASTER (5 } \\
\text { TIR, } \\
90 \mathrm{~m} \text { resolution) } \\
\text { Airborne sensor of } \\
\text { MAGI, 32 channels, } \\
2 \mathrm{~m} \text { resolution. }\end{array}$ & $\begin{array}{l}\text { ASTER could only map } \\
\text { general mineral groups } \\
\text { rather than } \\
\text { specific minerals. } \\
\text { The SEBASS and MAGI } \\
\text { allowed the detection } \\
\text { and quantification of } \\
\text { specific surface minerals } \\
\text { at geothermal fields. }\end{array}$ & $\begin{array}{l}\text { The space-borne sensors should be } \\
\text { launched with at least } 30 \text { spectral TIR } \\
\text { channels to allow for mapping of specific } \\
\text { minerals and surface units for } \\
\text { geothermal applications. }\end{array}$ \\
\hline 6 & $\begin{array}{l}\text { The geothermal } \\
\text { exploration in } \\
\text { Pyramid Lake } \\
\text { Paiute reservation } \\
\text { in northwestern } \\
\text { Nevada [32] }\end{array}$ & $\begin{array}{l}\text { ASTER and } \\
\text { HyMap sensor }(127 \\
\text { spectral channels, } \\
0.45-2.5 \mu \mathrm{m}, \\
5 \text { m resolution) }\end{array}$ & $\begin{array}{l}\text { Detect and map } \\
\text { geothermal indicator } \\
\text { minerals in the } \\
\text { proximity of structural } \\
\text { controls (faults and } \\
\text { thermal springs). } \\
\text { The mapped evaporates } \\
\text { (e.g., gypsum) and } \\
\text { chemical precipitates } \\
\text { (e.g., calcium carbonate). }\end{array}$ & $\begin{array}{l}\text { - Due to these minerals are produced from } \\
\text { the transport and physical processes } \\
\text { interacting with the unboiled fraction of } \\
\text { geothermal groundwater, } \\
\text { these maps could be used in modeling } \\
\text { subsurface fluid flow to derive } \\
\text { information on temperature and potential } \\
\text { locations of geothermal reservoirs. }\end{array}$ \\
\hline
\end{tabular}

The most direct evidence of geothermal activity that can be derived from remote sensing is the presence of surface manifestations such as calderas, hot springs, and fumaroles [47]. Mongillo [47] has used a range of multi-band combinations for the two datasets, combined with a priori knowledge of the study area, the authors were able to discern the larger geothermal surface features, noting the steam plumes from steaming grounds, large fumaroles, hot pools, and sinter deposits was shown in Table 1 . The authors used thermally stressed vegetation as a proxy variable for identifying smaller geothermal features. They highlighted the usefulness of TM band 5 (MIR, 1.55-1.75 $\mu \mathrm{m})$ for discriminating stressed vegetation and hybrid SPOT-TM composite image (R: TM Band 5, G: SPOT Band 2, B: SPOT Band 1). The use of vegetation proxies for identifying geothermal resources is further explored later in this section. The second form of direct evidence that can be derived from remote sensing is the very distinct signature of surface mineralogy in geothermal areas. The continuous emission of gas and hot water for several years leads to the alteration of soil and rocks along typically linear faults, fractures, and contact points. These regions of highest permeability are also the locations of the maximum densities of hydrothermally-altered minerals. In addition, the reactivity of the host minerals to alteration varies 
considerably, depending on the thermal and chemical characteristics of the interacting fluids. In fact, the majority of articles encountered in the literature search for this paper pertain to the application of mineral-mapping with multispectral and hyperspectral remote sensing for geothermal resource exploration. For a broad discussion of the use of hyperspectral imaging to mapping surface mineralogy, the reader is referred to [51]. Some researchers used data for the Long Valley caldera in the USA obtained with the Australian HyMap sensor, which samples the EM spectrum from wavelengths of 450 to $2500 \mathrm{~nm}$ in 126 separate but contiguous bands, varying from 13 to $17 \mathrm{~nm}$ wide each [48]. They produced sets of synoptic mineral maps. The authors confirmed that the presence of kaolinite-alunite assemblages in volcanic environments was due to a high temperature, vapor, acid-sulfate hydrothermal alteration. Their results showed that the hydrothermally-altered minerals followed a linear spatial distribution, coinciding with combining the hyperspectral mineral mapping results with data from geophysical surveys, the authors reported a good preliminary correlation between alteration at the surface and alteration at subsurface depths. a. Mia et al. [49] used the multispectral data from Landsat 7 ETM+ to map hydrothermal altered mineral deposits around the Kuju Volcano in Japan (Table 1). Their paper provides a noteworthy discussion of the conventional methods used for this particular type of mapping applications, namely: color composite, band ratio, principal component analysis, least square fitting, and reference spectra analysis methods. The image pre-processing involved geometric correction and georeferencing, using ground control points from topographic maps of 1:50,000 scale. False color composites (FCC) were created to map the target minerals using a combination of bands from the visible and infrared wavelengths to enhance their reflectance. The band ratio technique provides enhanced spectral contrasts among the bands used in the ratio operation and has been found to give unique information which is missing individual bands. The band ratio analysis revealed that there was a high concentration of iron minerals in the fumaroles region. Also, the principal components analysis (PCA) was used to reduce the dimensionality of correlated multispectral data to confirm the abundance of altered iron-oxide deposits near the fumaroles of the volcano. The least square fitting method is used to find regions of anomalous spectral response within an image dataset. The output image is the difference between the actual and modeled band value. The last technique employed by the authors is spectral reflectance analysis. They were able to identify specific hydrothermal altered minerals based on the library of mineral's known spectral reflectance published by the USGS. Another interesting paper on mineral mapping for geothermal exploration by remote sensing techniques is by [50]. The authors map mineral assemblages associated with geothermal activity at the Salton Sea in the USA. The authors compared mapping results from SEBASS, the space-borne sensor ASTER (5 TIR channels with a spatial resolution of $90-\mathrm{m}$ per pixel), and another airborne sensor. Their results reaffirmed that ASTER could only map general mineral groups rather than specific minerals. Meanwhile, the SEBASS and MAGI allowed the detection and quantification of specific surface minerals at geothermal fields. A similar paper combining the use of space-borne multispectral data from ASTER and airborne hyperspectral data, this time from the HyMap sensor (127 spectral channels between $0.45-2.5 \mu \mathrm{m}, 5 \mathrm{~m}$ per pixel spatial resolution), is [32]. They also did a field investigation to create separate maps for minerals which were not possible to spectrally differentiate. The authors found geothermal-indicator minerals in the proximity of structural controls such as faults, and thermal springs.

The optical data with moderate spatial resolution can be applied to identify the location of distribution of minerals based on surface manifestations. The previous studies showed the feasibility to measure wind fields by SARs data to estimate wind parameters in different approaches $[52,53]$. Table 2 shows the potential detection of various renewable energies. 
Table 2. The potential detection of various renewabale energies.

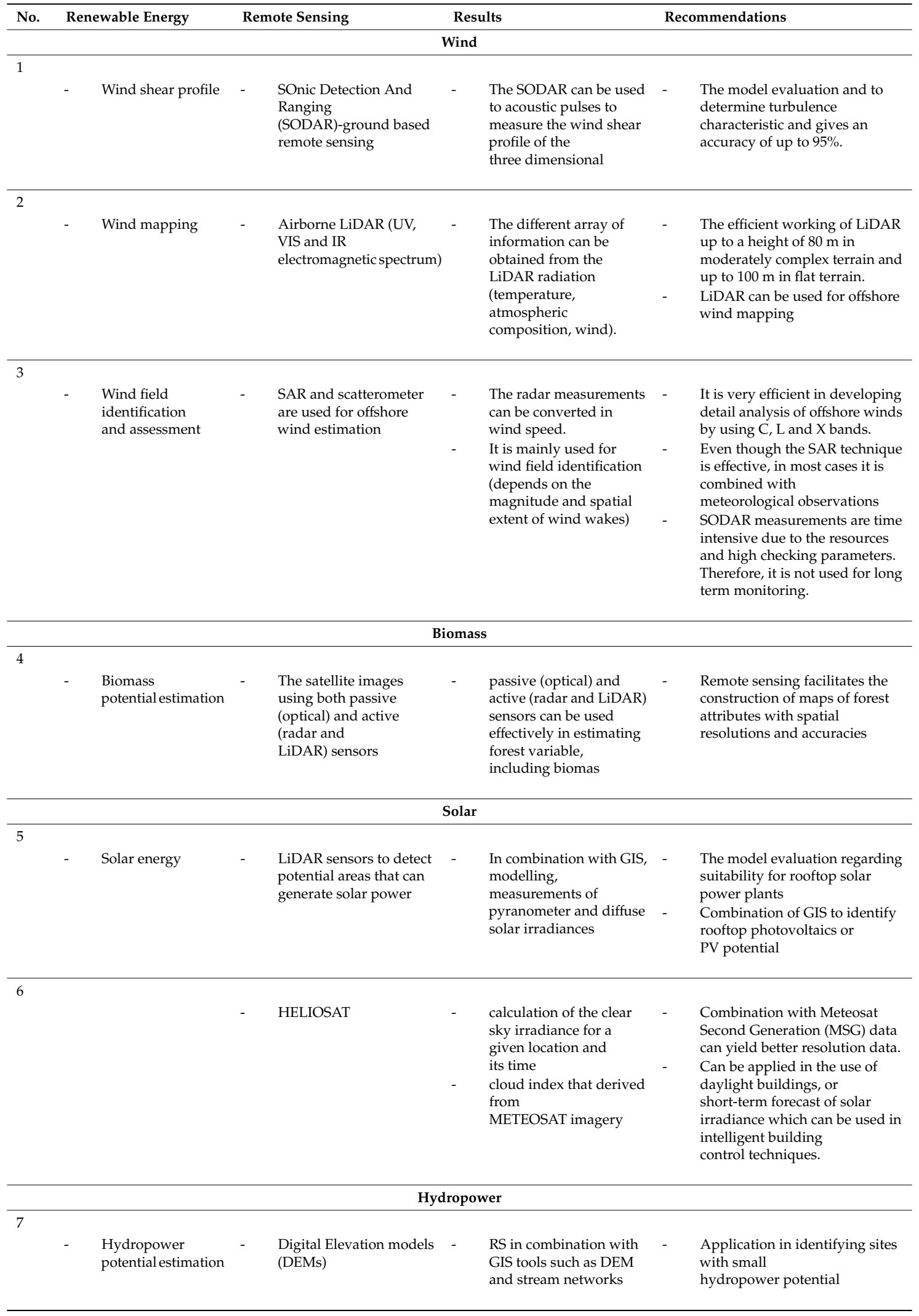

The SOnic Detection And Ranging (SODAR) is a ground-based remote sensing technology which use to measure wind characteristics. Therefore, the SODAR can be used to acoustic pulses to measure the wind shear profile of the three-dimensional in the lower atmospheric boundary layer. It can be 
used in remote sensing for micro-siting, model evaluation and to determine turbulence characteristic and gives an accuracy of up to $95 \%$. The mechanism works as SODAR listens the backscattered sound it is effective in determining the wind speed from the Doppler shift in acoustic frequency. During mapping, SODAR must be placed at a distance from the masts to eliminate the fixed echo interference. While comparing the other towers for calibrations the comparison shall be done locating it on a least uniform surface. Temperature or precipitation can have an impact on the accuracy of SODAR images. Studies have shown SODAR measurements are time intensive due to the resources and high checking parameters. Therefore, it is not used for long term monitoring. The remote sensing data such as airborne LiDAR was considered effective for detection of temperature, atmospheric composition, wind, etc. by using different radar scattering $[12,54,55]$. Studies have shown the efficiency of LiDAR data up to a height of $80 \mathrm{~m}$ in moderately complex terrain and up to $100 \mathrm{~m}$ in flat terrain. It enables measurement of the speed of incoming wind before it interacts with wind turbine rotor. This preview technique can be used to reduce the loads on wind turbines. The LiDAR units which are mounted on nacelle or on turbine rotor and it can scan wind field up to $200 \mathrm{~m}$. Air-borne techniques make use of SAR, which can be used for offshore wind mapping. It is very efficient in developing detail analysis of offshore winds by using C, L and X bands. In most of the cases, SAR and scatterometer are used for offshore wind estimation. These radars are capable of sensing ripples at the surface of the sea generated by the wind. The radar measurements can be converted in wind speed. Even though the SAR technique is effective, in most cases it is combined with meteorological observations.

Remote sensing is being used either in the estimation of biomass potential, availability and feasibility for production or the site selection of the power plants and the biomass plantation, nearest to the grid line and biomass transportation cost on the basis of the quantity of biomass and transportation distance [30]. The forest residual biomass is a source of renewable energy, which includes branches, and un-merchantable stem tops that are commercially not suitable for timber exploitation [56]. This biomass can be used as a source of energy in heating applications (fuel for domestic or industrial stoves and boilers) and also for the electricity generation. The use of forest residual biomass has two types of benefits. The benefits in term of both social and economic come from the use of forest residual biomass are the reduction in the use of fossil fuels in national scale and creation of rural employment by increasing harvests, transportation, and utilization in power stations in local scale. However, the lack of methodologies to assess the quantity of forest residual biomass is one of the main problems.

The satellite images using both passive (optical) and active (radar and LiDAR) sensors can be used effectively in estimating biomass, series of SHP, and locate the potential areas for solar power. Ground verification is still required before any application of any obtained data. The remote sensing and GIS as a decision-making tool, has facilitated combining evaluations of environmental, social and political constraints with engineering decisions to produce the best alternative decisions. We have also seen how those tools helped some governments in decision-making or in convincing investors to consider energy from solar panels as an option. Those concrete examples are only a few among many more which prove the practical use of remote sensing and GIS.

\section{Cases Studies}

Figure 5 shows a flowchart with application of remote sensing in exploring renewable energy resources. The explainataion about each case study is given below. 


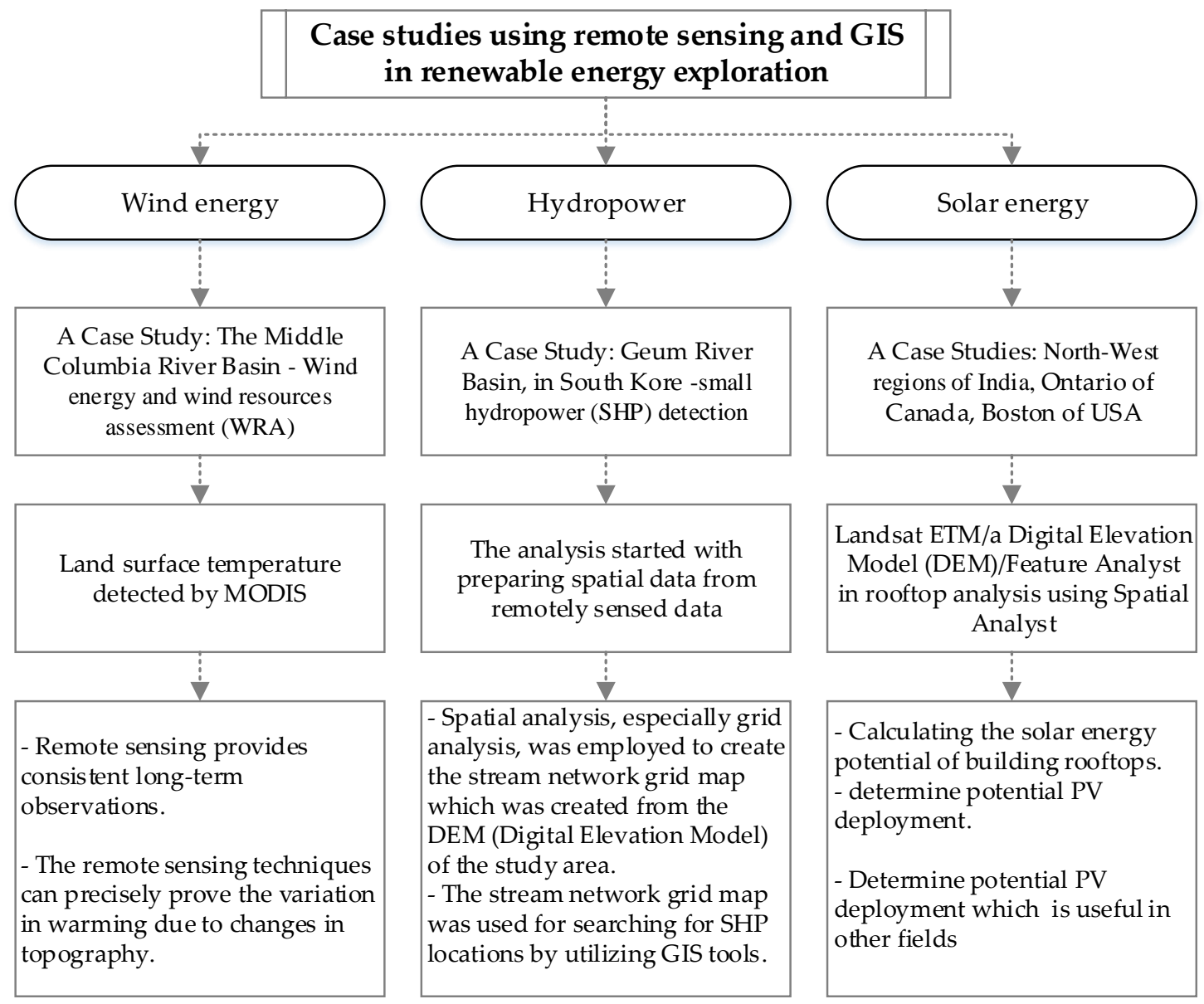

Figure 5. Flowchart of application of remote sensing in exploring renewable energy resources.

\subsection{Wind Energy Case Studies}

For the wind energy assessments and measurement of factors like speed, power, density, prevailing direction seasonal variation and long-term consistency are important. This analysis is known as wind resource assessment (WRA). Different applications and scales require WFA at different hub heights. A case study was chosen from the Middle Columbia River Basin and the land surface temperature results are obtained from MODIS.. The grid system is used due to its ease in operation. As most of the data were available in raster format, it needed to be converted in grid-based raster using ArcGIS. A unified grid size was chosen. Features datasets like administrative, infrastructure and environmental were included in a geodatabase. The analysis was carried out in three stages.

- $\quad$ Stage 1: The rasters were manually converted to a binary scale using the reclassify tool. The buffer zone was segregated. The output was then combined into a single layer.

- Stage 2: All the layers obtained were re-classified to a scale which were compatible with weighted overlay.

This approach is efficient because one layer could be used multiple times on multiple layers, giving consistent geographical boundaries for the selection of site. The output raster was transformed into polygons to calculate the geographic area [57]. The mechanism of wind turbines extracts the kinetic energy from the atmosphere to generate electricity. Due to the vertical mixing and enhanced turbulence, a substantial impact is seen on the local meteorology. As the surface temperature measurements are not easy to obtain from the data available. Therefore, spatial and temporal data is not sufficient for studying wind energy impacts at large scales. In such conditions, remote sensing provides consistent long-term observations. Further classification of the data resulted in the outcomes of wind farms 
and their impact on the local meteorology. The remote sensing techniques also precisely proved the variation in warming due to changes in topography.

\subsection{The Series Small Hydropower (SHP) Detection Case Studies}

The small hydropower can provide local energy and series small hydropower plants were detected by remote sensing in Korea by Yi et al. [58]. The aim of this part of study was to suggest a new location analysis method in an attempt to search for possible small hydropower sites using remote sensing. The six potential small hydro power sites were explored at the Geum River Basin, in South Korea. This study would be useful in the future activation for development of small hydro power sites. With the sustainability of small hydropower (SHP) development being more significantly emphasized, this study focused on social, economic and environmental dimensions which are the three basic dimensions of sustainability. In addition, several investigations were performed for the analysis of small hydro power sites using remote sensing data and GIS. The analysis started with preparing spatial data from remotely sensed data, some of which were used to create a stream network grid map, while other data is used to perform an overlay analysis. Spatial analysis, especially grid analysis, was employed to create the stream network grid map which was created from the DEM (Digital Elevation Model) of the study area. The stream network grid map was used for searching for SHP locations by utilizing GIS tools [58]. This study has successfully applied location analysis of SHP which can help overcome the limitation of traditional methods of outside survey.

\subsection{The Solar Energy Case Studies}

With this rapid population increase and this global migration to cities, the need for energy is alarming. Cities are known to be more crowded than other areas, which implies the fact the space is sometimes limited. It also means that with high buildings, it is unlikely to install photovoltaic (PV) panels on the ground and to expect to generate full solar energy potential in the area. For that reason, a certain government requires the study of rooftops to PV deployment which can help to reduce greenhouse gas emissions [59]. These case studies of India, Ontario, Canada, and Boston USA were conducted. at the aim of developing more renewable energy in order to reduce the dependence on fossil fuels that will deplete with the time anyway. It should be noted that only LiDAR data or combination with other techniques (GIS, modelling, measurements of pyranometer and diffuse solar irradiances) to find out the potential of a roof's surface [12,59]. LiDAR data was applied by [12] to successfully determine a rating list of roofs' surfaces in urban region by PV systems as well as enable estimating potential of solar electricity can be obtained based on the location [60].

By the request of the Ministry of New and Renewable Energy (MNRE) of India, many types of research are done in order to get accurate information on solar radiation availability [61]. In this specific paper entitled "Solar Resource Assessment using GIS \& Remote Sensing techniques" the area chosen is the North-West regions of India. The surface is studied because the amount of radiation differs from one place to another, therefore in order to get accuracy, certain factors have to be considered, such as latitude, time of the year, elevation and slope. The first step was to get a Digital Elevation and images of the region from Landsat ETM. Then, they used ArcGIS along with the Spatial Analysis extension to calculate Watt-Hours/ meter square at the surface at the local scale. They used the Solar Analyst to accumulate the energy that strikes the earth's surface for one hour prior to the acquisition of the Landsat image. They followed by comparing the amount of energy available at the surface to the brightness-temperature derived from Landsat thermal band. Other researchers have also shown other methods used to calculate the surface solar irradiance from satellite imageries. Indeed, in the paper entitled "Solar Energy Assessment Using Remote Sensing" the authors give an example of methodology used in remote sensing technology called HELIOSAT used in Europe. It is said to be possibly applied in the use of daylight buildings, or in the development of a short-term forecast of solar irradiance which can be used in intelligent building control techniques among its other uses. HELIOSAT was first introduced in [62] and was modified later by [63]. The work starts with the 
calculation of the clear sky irradiance for a given location and its time. It is followed by a cloud index that derived from METEOSAT imagery (Geostationary satellite). The papers give a very empirically detailed explanation of the method. Researchers have also taken advantages on the launch of a new European meteorological satellite MSG (Meteosat Second Generation) in 2002. From that launch, they were able to explain how HELIOSAT will be of a better used. Indeed, MSG offers traditional channels and a higher resolution. This leads to a improved depiction of the radiative transfer from the atmosphere. Moreover, cloud detection will be done in a more accurate way, thanks to the higher spatial and temporal resolution.

A research was done at Ontario of Canada to identify the usability of rooftops as a base for PV employment. The paper entitled "Quantifying rooftop solar photovoltaic potential for a regional renewable energy policy", specifically identifies the advantage of GIS as a means to locate potential locations. The paper used GIS as well as advanced features extraction algorithms in order to allow a better comprehension of building distribution and form in a specific "Renewable Energy Region" of Ontario, more specifically the southeastern part of the region. The total estimation of total rooftop photovoltaics or PV potential was done following step procedure, involving a geographical division of the area. The first step was to sample by using the Feature Analyst extraction software. The second step was to extrapolate using roof area-population relationships, followed by the third step being the reduction for shading, other uses, and orientation, the conversion to power and energy outputs. After comparing these results to similar numbers found in other parts of the world, it showed that Canadian settlements have a low-density character, as well as a high abundance of roof area. Detaining this information is important since it helps to determine potential PV deployment in the region. Furthermore, it helps it is useful in other fields in which it helps, for instance, better inform of policy surrounding other applied sustainable initiatives (stormwater runoff, thermal applications, green-roof deployment, etc.). "Potential peak power outputs for the region with rooftops covered with PV range from 2.05-5.74 GW, depending on the panel efficiencies used. Potential annual energy production ranges from 2474-6909 GWh" [36]. Though only 5\% of total annual energy demand can be met only with rooftops, this number could be higher and reach $30 \%$ if rooftop deployment is done on a larger scale such as province-wide for instance. The conclusion is that the Ontario Feed-In Tariff can potentially initiate significant renewable energy inputs to the Ontario grid. By detaining this information, it facilitates decision-making and policy formulation. It, therefore, brings a higher probability of seeing a shift of focus toward the establishment of solar photovoltaics in the region, and across the entire country. Another study of using a new method of LiDAR and GIS links to hourly Daysim simulations to predict city-wide electricity gains from photovoltaic panels which were conducted by [59]. This study showed good prediction rooftop temperatures for calculating hourly PV efficiency in Cambridge, USA.

A similar path, the city of Boston of USA adopted in 2007. Indeed, the mayor was attempting to reduce the consumption of energy by the city through fossil fuels and to instead reach their goal of a more sustainable future by expanding the use of solar panels. In order for that goal to be reached, designed researchers used web GIS and remote sensing as tools to display their findings on optimal areas for PV deployment. Web GIS helped track the progress of citywide solar installations. Then, another tool used was ArcGIS Spatial Analyst to calculate the solar radiation available on building rooftops. This solar radiation tool helped in calculating the solar energy potential of building rooftops. The ArcGIS API for Flex was the final medium where the application was wrapped in a user-friendly format. They followed by building a digital elevation model (DEM) of the city that enabled to then model incoming solar radiation considering variation in elevation, orientation, the shadows cast by topographic features, and changes with the time of day or year [64].

\section{Discussion}

A number of publications have demonstrated significant correlations between surface temperature, heat flux, vegetation cover, and land deformation to the presence of geothermal resources. This indirect evidence, whose reliability is much dependent on ground verification and cross-validation with 
numerical modeling and other methods, will be described in this section of the paper. Majority of the literature dealing with mapping surface temperature for geothermal applications revolve around the use of thermal infrared (TIR) remote sensing using the ASTER datasets. A fundamental paper of this subject is [65]. The authors developed a methodology for processing the ASTER images to highlight the subsurface contributions of geothermal heat by minimizing the effect of diurnal temperature variations. They proposed empirical relationships to model the influence of the physical properties (thermal inertia, albedo, emissivity, moisture content) of different surface materials. The authors also employed a methodology to minimize the effect of topographic slope on temperature variation, using a DEM from the US Geological Survey. The authors recommended the use of their image processing chain for the situations where thermal anomalies over large regions need to be searched or where topographic slopes are relatively steep. Related to this aspect of isolating the geothermal sources of temperature anomalies, Ref. [66] proposed a new model that includes a parameter to include the influence of temperature variation with ground surface altitude, and applied this using ASTER images of two geothermal complexes in the Andes. The effect of altitude on temperature was modeled as a linear relationship. The thermal anomalies identified were successfully cross-checked using field measurements of atmosphere and ground surface temperature, as well as radiation for albedo calibration. The authors stated that surface manifestations larger than $90 \mathrm{~m}^{2}$ can be detected, but smaller ones $\left(<60 \mathrm{~m}^{2}\right)$ or with small thermal anomaly $\left(\Delta \mathrm{T}<5^{\circ} \mathrm{C}\right)$ could not be identified. They also recommended the use of nighttime TIR images, since this record higher temperature contrast between geothermal areas and surroundings. Another pioneering publication, particularly on the limits of spatial resolution, is $[33,67]$. Although primarily formulated to monitor thermal anomalies for mitigating volcanic hazards, the paper is relevant considering that, as stated earlier, surface manifestations of geothermal resources are typical of sub-pixel size. A so-called "thermal mixing detection threshold" was calculated to quantify the limits of ASTER's ability to resolve sub-pixel thermal mixing over a range of hot target temperatures and \% pixel areas. After applying the model to the Yellowstone National Park and Erebus volcano, the authors concluded that ASTER TIR data can be used for modeling sub-pixel thermal characteristics, but the results are extremely sensitive to errors in measurement and validity of the assumptions. The authors recommended measurements of thermal features and surface compositions in order to reduce the magnitude of uncertainties. Meanwhile, apart from ASTER, TIR data from the Landsat ETM+ sensor can also be used in a similar application. The authors in [68] used Landsat 7 ETM+ TIR data to identify land surface temperature (LST) anomalies and locate geothermal areas in China. Their methodology for deriving LST is summarized as shown in Figure 2. The principal steps involved were radiometric calibration, atmospheric correction, and emissivity calculation. The authors then applied a mechanistic analysis to the derived LST information, combining these with results from the previous heat source and geological investigations to locate geothermal features in their study area. Another application of TIR datasets, also closely linked with surface temperature, is in the monitoring of geothermal heat flux. Likewise, monitoring of surface heat loss throughout the management of a geothermal power plant can serve as an indicator of unsustainable fluid extraction rates. Geothermal heat flux (GHF) can be conventionally measured from boreholes through the use of thermocouples. Recently, remote sensing for this type of application has been gaining momentum [69] used high spatial resolution ( 1 m pixel size) airborne TIR imagery to calculate heat flux from hot springs, utilizing a simplified, steady-state heat budget model. The volumetric discharge rates from these springs were also calculated using these images and showed that this was a good method in comparison with field-derived estimates. Meanwhile, Ref. [33] used ASTER TIR data (90 m per pixel) to quantify the radiant GHF at the Yellowstone National Park, and MODIS TIR data (1 km per pixel) to investigate long term changes in GHF and establish thermal change detection limits, so as to retrieve information on significant anomalies that could be a result of impending volcanic eruption or anthropogenic interventions. Ref. [70,71] demonstrated the use of Landsat ETM+ imagery to quantify GHF estimates at the Yellowstone National Park. The latter paper, however, recognized that the estimation of absolute GHF from Landsat images is severely restricted without a number of 
supplementary parameters, due to the influence of both direct and indirect solar radiation, and albedo. Similarly, some researchers used Landsat TIR data to monitor heat flux at a geothermal field in New Zealand [72]. By comparing images 1990 and 2011 images, they were able to detect a $7 \mathrm{MW}$ reduction in geothermal radiative heat flux. Incidentally, a vegetation index study they conducted revealed a progressive increase in the area of healthy vegetation during the same time interval. The authors inferred that this was a reasonable phenomenon since the health of thermally-stressed vegetation has an inverse relationship to the shallow ground temperature. On the same note, Ref. [73] remarked that there are distinctive ecosystems associated with geothermal features. Based on an analysis of ecological characteristics in the Taupo Volcanic Zone in New Zealand, the author concluded that vegetation zones occur in a predictable pattern along the soil temperature gradient. The same is true for the longitudinal distribution of aquatic flora and fauna downstream of thermal springs and vertically on geysers. Also, due to the characteristics of geothermal fields (steep soil temperature gradient, exposure to steam, highly mineralized soil \& water, extreme $\mathrm{pH}$, low amount of organic matter), the vegetation communities in such areas tend to exhibit slow relative growth rates, smaller leaves and shallower roots, sporadic flowering, and smaller plant size in general. Given this knowledge of distinctive vegetal attributes in geothermal ecosystems, it can be reasonably inferred that such information can be employed in remotely-sensed data to locate potential geothermal sites. However, there has been little published literature on such applications. Ref. [74] conducted a vegetal-spectral field survey using a GER 2100 spectroradiometer to determine if substantial differences in vegetation spectra to indicate stress or damage could be detected. The indicators used to determine spectral anomalies in stressed vegetation were the inflection point of the red-edge reflectance, the red-edge shoulder reflectance minus the red minimum reflectance, the $699 / 765 \mathrm{~nm}$ ratio, and the position of the visible green maximum reflectance. Their results indeed revealed spectral response anomalies in stressed vegetation, and mapping these anomalous plants showed that their distribution could be correlated to geophysical faults and geothermal activities. This study suggests that high-resolution hyperspectral data might be a feasible option to undertake similar analyses for geothermal applications. The last form of indirect evidence of geothermal resources that can be derived from remote sensing is land surface deformation, which can be obtained from SAR interferometry (InSAR). In particular, this method can be useful during the active management of the geothermal plant, as it can also serve as an indicator of over-extraction. It has been reported that geothermal exploitation may lead to land surface deformations, particularly due to reservoir depletion and the associated seismicity that is induced. Ref. [75] used radar images from European Remote Sensing (ERS) satellites, ERS-1 and 2 to monitor ground subsidence related to activities at the Coso geothermal area in the USA. The raw ERS data were processed with the "two-pass" and "four-pass" methods, which remove topographic effects using a DEM and two InSAR pairs acquired in tandem, respectively. These yielded similar results, indicating sufficient accuracy. The authors then inverted the observed surface displacements using a finite spheroidal source model to locate the positions, geometry, and strengths of pressure sources. The observed ground subsidence of $\sim 3-4 \mathrm{~cm} / \mathrm{yr}$ occurred over an area of $\sim 50 \mathrm{~km}^{2}$, and the source depths indicated by the simulations range from 1 to $3 \mathrm{~km}$. These values correspond to the production area and depths of the Coso geothermal plant, indicating that such deformations are likely the results of geothermal reservoir cooling and/or depletion. Furthermore, analysis of consecutive interferograms indicates that the depths and horizontal extent of the surface deformations may increase with time, presumably reflecting a trend towards unsustainable geothermal exploitation. Ref. [76] also used ERS-1 and 2 radar images in the C-band (56 mm wavelength) to study the subsidence at the Cerro Prieto geothermal field in Mexico. Their simulations similarly revealed that the source of the ground subsidence is related to compaction of the geothermal reservoir due to fluid extraction. These results were improved by [77], using Differential InSAR (DInSAR) analysis applied to ENVISAT ASAR C-band data. Interferometric processing was accomplished with the DORIS InSAR package of the Delft Institute for Earth-oriented Space Research. The DInSAR results were also compared to and yielded good agreements with ground-based geological investigations and geodetic leveling 
measurements. The authors suggested that planned future increase in fluid extraction and expansion of geothermal field limits would likely lead to increased ground subsidence. In contrast to subsidence, Ref. [78] reported urban uplift in Staufen im Breisgau, Germany caused by geothermal development, leading to significant damages to buildings in the city. In this case, the drilling of geothermal boreholes caused interaction between anhydrite deposits and groundwater. This leads to recrystallization of the anhydrite into gypsum, a transformation which involves a swelling process of up to $60 \%$ increase in volume [79]. The authors applied the InSAR Small Baseline Subset (SBAS) approach to X-band radar images from the TerraSAR-X satellite, which has a spatial resolution of $3 \mathrm{~m}$ and a revisit time of 11 days. The SBAS approach enables multi-temporal measurements of surface displacements of up to millimeter-level accuracy. The authors compared the results of this analysis with geodetic leveling measurements, and showed good, albeit partial, correspondence. This particular study shows the feasibility of using high temporal resolution datasets to monitor the rapid uplift rates in the study area. The results could be used for planning appropriate countermeasures, as well as for making proper management decisions on the future of the geothermal plant in the area.

Remote sensing technology has proven to be a cost-effective method from the locations which has accessibility challenges. The cost-benefit analysis considers the installation costs of the mast and the cumulative costs of the remote sensing instruments, for data acquisition in a given time frame. Along with the location of site remote sensing weighs over the mast techniques by providing additional information, such as wind shear extrapolation over rotor disc of a large wind turbine project, or horizontal extrapolation across multiple locations. After acquiring the data, the RS techniques combine Multi-Criteria Spatial Decision Support System (MC-SDSS) in collaboration in spatial planning. After obtaining the data from remote sensing, the multi-criteria spatial data analysis methodology is used in GIS. This process can be described as transforming the geographical-referenced data into the resultant decision. The data obtained is generally arranged in vector or raster format, known as maps or layers in GIS. Often, Multicriteria analysis is also referred to as multi-criteria evaluation (MCE). The basic principle of MCE is to analyze a finite number of choice possibilities with respect to multiple criteria and different objectives. The multi-criteria analysis methods can be of different types such as deterministic or probabilistic, depending on the multiple objectives. The final result of this analysis is a site suitability map generated after evaluating different criteria affecting the project. The overlay methods are used for site selection.

The use of satellite data definitely needs a ground truth survey and also apparently need to conduct point survey for the assessment of biomass resources. The aboveground biomass is normally estimated using allometric equations that related to the tree data, usual diameter at breast height (DBH) and height for specific tree species and geographic location. It is necessary to develop the specific forest residual biomass regressions for each species for application to pre-existing tree dimension data. To avoid complexity associated with the mixture of tree species in the spectral data of the Landsat image, it needs to be monoculture forest. The cartography not only allows the calculation of the total amount of forest residual biomass resource but also suitable for determining technical and economic feasibility for example slope, distance to the forest tracks, area of the forest stands. There is a limitation to using remotely sensed data in the estimation of forest residual biomass are relating to; only feasible in monoculture forest and field operation has to be conducted, inaccuracies related to heterogeneity. However, despite all these limitations, the size of the scenes and cheap distribution, make remote sensing the most suitable for estimation of forest residual biomass (FRB) [80]. The below-ground biomass is larger than above-ground biomass, but it is impossible to estimate their magnitude directly with the existing remote sensing system. The Normalized Difference Vegetation Index (NDVI) relating to the reflectance properties of active photosynthetic plant tissue in the red and near-infrared portion of the electromagnetic spectrum is a very common index using the studies of agriculture and forest. Even though NDVI is well-related to the total biomass in the agricultural and forestry land but these might neglect the presence of dead plant material. The direct estimation of carbon storage in moderate to high biomass forests is a major challenge for remote sensing with the conventional optical and radar 
sensors for ecological applications, thus the use of LiDAR is an alternative remote sensing method that increases the accuracy of biophysical measurements. LiDAR sensors measure 3D distribution of plant canopies, therefore providing high resolution topographic maps and accurate estimates of canopy structure. Also, LiDAR sensors can estimate aboveground biomass in situations where the conventional sensors can not perform well [81]. For the suitability and optimality of site analysis, remote sensing is used to reduce the transportation cost, which is the primary concern in the new power plant planning in order to optimize allocation and supply-area consideration. Location-allocation of the plant bases on all usable biomass in the area. Two measurements, usable biomass, and efficiency can be used to compare the supply areas.

\section{Conclusions}

The moderate spatial resolution satellite with thermal infrared band such as ASTER, Landsat can be effectively used to detect the potential distribution of general shallow geothermal resources. It was understood that remotely-sensed data can serve as direct or indirect evidence of geothermal activity, which was proven through the different applications of various remote sensing techniques, such as multispectral, hyperspectral, thermal and microwave remote sensing. Development of wind energy strongly depends on remote sensing and GIS technologies to optimize its potential. The SODAR, LiDAR, and SAR are useful to identify optimal conditions for wind power development, such as the wind power density, or its proximity to the electric grid among others. Among these SAR data is also useful for mapping of mineral, biomass and solar energies. The satellite images use both passive (optical) and active (radar and LiDAR) sensors to effectively estimate various forest biophysical parameters. SAR is also useful in developing detailed analysis of offshore winds for wind assessments. The satellite images use both passive (optical) and active (radar and LiDAR) sensors to effectively estimate various forest biophysical parameters for biomass estimation.

In the case of hydrothermal energy, selection of a site seems very tricky, which means that remote sensing and GIS technologies are of great need. Remote sensing and GIS techniques also play a vital role in development of solar energy projects by providing potential sites for installation of solar panels. A new remote sensing technology known as HELIOSAT, which deals with atmospheric and cloud extinction separately is also widely used in solar energy resource development. It was shown how remote sensing and GIS techniques are useful for rooftop photovoltaic panel installation in urban areas. In a nutshell, using remote sensing techniques, not only increase speed, cost effectiveness, precision, and timeliness for estimation of various parameters of various parameters used in different renewable energy resources exploration but also provide multi spatio-temporal information. We also saw in detail that satellite and DEM data were used in various case studies. Further, it was explained that remote sensing is becoming cost effective, less time consuming as compared to conventional surveying. Though, there is still a need for an in-situ data for the validation of the satellite-based outcomes as well as physical and mathematical modeling.

Author Contributions: Conceptualization, R.A., A.K.A., S.C., N.S.; methodology, R.A., A.K.A.; investigation, R.A., A.K.A., S.C., N.S.; writing R.A., A.K.A., S.C., N.S., A.K., A.P.Y., J.D., T.A.K.; writing-review and editing, R.A., A.K.A., S.C., N.S., A.K., A.P.Y., J.D., T.A.K.

Funding: This research received no external funding.

Acknowledgments: The authors is grateful to the Faculty of Environmental Earth Science, Hokkaido University for facilities, and anonymous reviewers for their comments. The authors would like to acknowledge their colleagues and students for useful discussion and contribution during this study. Sahu is a JSPS fellow at Kyoto University.

Conflicts of Interest: The authors declare no conflict of interest. 


\section{References}

1. Ellabban, O.; Abu-Rub, H.; Blaabjerg, F. Renewable energy resources: Current status, future prospects and their enabling technology. Renew. Sustain. Energy Rev. 2014, 39, 748-764. [CrossRef]

2. Avtar, R.; Tripathi, S.; Aggarwal, A.K.; Kumar, P. Assessment of Energy-Population-Urbanization Nexus with Changing Energy Industry Scenario in India. Land 2019, 8, 124. [CrossRef]

3. Avtar, R.; Tripathi, S.; Aggarwal, A.K.; Kumar, P. Population-Urbanization-Energy Nexus: A Review. Resources 2019, 8, 136. [CrossRef]

4. Akhtar, F.; Rehmani, M.H. Energy replenishment using renewable and traditional energy resources for sustainable wireless sensor networks: A review. Renew. Sustain. Energy Rev. 2015, 45, 769-784. [CrossRef]

5. Bhattacharya, M.; Paramati, S.R.; Ozturk, I.; Bhattacharya, S. The effect of renewable energy consumption on economic growth: Evidence from top 38 countries. Appl. Energy 2016, 162, 733-741. [CrossRef]

6. van der Meer, F.; Hecker, C.; van Ruitenbeek, F.; van der Werff, H.; de Wijkerslooth, C.; Wechsler, C. Geologic remote sensing for geothermal exploration: A review. Int. J. Appl. Earth Obs. Geoinf. 2014, 33, 255-269. [CrossRef]

7. Forsberg, C.W. Sustainability by combining nuclear, fossil, and renewable energy sources. Prog. Nucl. Energy 2009, 51, 192-200. [CrossRef]

8. Lund, J.W.; Bjelm, L.; Bloomquist, G.; Mortensen, A.K. Characteristics, development, and utilization of geothermal resources. In Geo-Heat Center Bulletin; Oregon Institute of Technology: Klamath Falls, OR, USA, 2007.

9. Pruess, K. Enhanced geothermal systems (EGS) using $\mathrm{CO}_{2}$ as working fluid-A novel approach for generating renewable energy with simultaneous sequestration of carbon. Geothermics 2006, 35, 351-367. [CrossRef]

10. Martini, B.; Silver, E.; Pickles, W.; Cocks, P. Hyperspectral Mineral Mapping in Support of Geothermal Exploration: Examples from Long Valley Caldera, CA and Dixie Valley, NV, USA; Lawrence Livermore National Lab. (LLNL): Livermore, CA, USA, 2003; Volume 27.

11. Karthikeya, B.R.; Negi, P.S.; Srikanth, N. Wind resource assessment for urban renewable energy application in Singapore. Renew. Energy 2016, 87, 403-414. [CrossRef]

12. Lukač, N.; Žlaus, D.; Seme, S.; Žalik, B.; Štumberger, G. Rating of roofs' surfaces regarding their solar potential and suitability for PV systems, based on LiDAR data. Appl. Energy 2013, 102, 803-812. [CrossRef]

13. Kilic, G.; Unluturk, M.S. Testing of wind turbine towers using wireless sensor network and accelerometer. Renew. Energy 2015, 75, 318-325. [CrossRef]

14. Johannessen, O.; Korsbakken, E. Determination of wind energy from SAR images for siting windmill locations. Earth Obs. Q. 1998, 59, 2-4.

15. Zhang, H.; Wang, J.; Xie, Y.; Yao, G.; Yan, Z.; Huang, L.; Chen, S.; Pan, T.; Wang, L.; Su, Y.; et al. Self-Powered, Wireless, Remote Meteorologic Monitoring Based on Triboelectric Nanogenerator Operated by Scavenging Wind Energy. ACS Appl. Mater. Interfaces 2016, 8, 32649-32654. [CrossRef] [PubMed]

16. Harris, R.; Zhou, L.; Xia, G. Satellite observations of wind farm impacts on nocturnal land surface temperature in iowa. Remote Sens. 2014, 6, 12234-12246. [CrossRef]

17. Kim, D.; Kim, T.; Oh, G.; Huh, J.; Ko, K. A comparison of ground-based LiDAR and met mast wind measurements for wind resource assessment over various terrain conditions. J. Wind Eng. Ind. Aerodyn. 2016, 158, 109-121. [CrossRef]

18. Mikkelsen, T.; Angelou, N.; Hansen, K.; Sjöholm, M.; Harris, M.; Slinger, C.; Hadley, P.; Scullion, R.; Ellis, G.; Vives, G. A spinner-integrated wind lidar for enhanced wind turbine control: Spinner-integrated wind lidar for enhanced steering and control. Wind Energy 2013, 16, 625-643. [CrossRef]

19. Shen, G.; Xu, B.; Jin, Y.; Chen, S.; Zhang, W.; Guo, J.; Liu, H.; Zhang, Y.; Yang, X. Monitoring wind farms occupying grasslands based on remote-sensing data from China's GF-2 HD satellite-A case study of Jiuquan city, Gansu province, China. Resour. Conserv. Recycl. 2017, 121, 128-136. [CrossRef]

20. Lovett, A.A.; Sünnenberg, G.M.; Richter, G.M.; Dailey, A.G.; Riche, A.B.; Karp, A. Land Use Implications of Increased Biomass Production Identified by GIS-Based Suitability and Yield Mapping for Miscanthus in England. BioEnergy Res. 2009, 2, 17-28. [CrossRef]

21. Lefsky, M.A.; Cohen, W.B.; Harding, D.J.; Parker, G.G.; Acker, S.A.; Gower, S.T. Lidar remote sensing of above-ground biomass in three biomes. Glob. Ecol. Biogeogr. 2002, 11, 393-399. [CrossRef]

22. Kumar, L.; Mutanga, O. Remote Sensing of Above-Ground Biomass. Remote Sens. 2017, 9, 935. [CrossRef] 
23. Voivontas, D.; Assimacopoulos, D.; Koukios, E. Aessessment of biomass potential for power production: A GIS based method. Biomass Bioenergy 2001, 20, 101-112. [CrossRef]

24. Le Toan, T.; Beaudoin, A.; Riom, J.; Guyon, D. Relating forest biomass to SAR data. IEEE Trans. Geosci. Remote Sens. 1992, 30, 403-411. [CrossRef]

25. Roy, P.S.; Ravan, S.A. Biomass estimation using satellite remote sensing data-An investigation on possible approaches for natural forest. J. Biosci. 1996, 21, 535-561. [CrossRef]

26. Shi, X.; Elmore, A.; Li, X.; Gorence, N.J.; Jin, H.; Zhang, X.; Wang, F. Using spatial information technologies to select sites for biomass power plants: A case study in Guangdong Province, China. Biomass Bioenergy 2008, 32, 35-43. [CrossRef]

27. Evans, A.M.; Finkral, A.J. From renewable energy to fire risk reduction: A synthesis of biomass harvesting and utilization case studies in US forests. GCB Bioenergy 2009, 1, 211-219. [CrossRef]

28. Juwarkar, A.A.; Varghese, A.O.; Singh, S.K.; Aher, V.V.; Thawale, P.R. Carbon sequestration potential in above ground biomass of natural reserve forest of Central India. Int. J. Agric. Res. Rev. 2011, 1, 80-86.

29. Avtar, R.; Suzuki, R.; Takeuchi, W.; Sawada, H. PALSAR 50 m Mosaic Data Based National Level Biomass Estimation in Cambodia for Implementation of REDD+ Mechanism. PLoS ONE 2013, 8, e74807. [CrossRef] [PubMed]

30. Kusre, B.; Baruah, D.; Bordoloi, P.; Patra, S. Assessment of hydropower potential using GIS and hydrological modeling technique in Kopili River basin in Assam (India). Appl. Energy 2010, 87, 298-309. [CrossRef]

31. Biggs, D.; Miller, F.; Hoanh, C.T.; Molle, F. The delta machine: Water management in the Vietnamese Mekong Delta in historical and contemporary perspectives. In Contested Waterscapes in the Mekong Region; Hydropower, Livelihoods and Governance; Routledge: Abingdon-on-Thames, UK, 2009; pp. 203-225.

32. Kratt, C.; Calvin, W.M.; Coolbaugh, M.F. Mineral mapping in the Pyramid Lake basin: Hydrothermal alteration, chemical precipitates and geothermal energy potential. Remote Sens. Environ. 2010, 114, 2297-2304. [CrossRef]

33. Vaughan, R.G.; Keszthelyi, L.P.; Lowenstern, J.B.; Jaworowski, C.; Heasler, H. Use of ASTER and MODIS thermal infrared data to quantify heat flow and hydrothermal change at Yellowstone National Park. J. Volcanol. Geotherm. Res. 2012, 233, 72-89. [CrossRef]

34. Al-Mukhtar, M.; Al-Yaseen, F. Modeling Water Quality Parameters Using Data-Driven Models, a Case Study Abu-Ziriq Marsh in South of Iraq. Hydrology 2019, 6, 24. [CrossRef]

35. Datta, A.; Karakoti, I. Solar resource assessment using GIS \& remote Sensing techniques. ESRI India 2010, 9560272741, 1-20.

36. Wiginton, L.K.; Nguyen, H.T.; Pearce, J.M. Quantifying rooftop solar photovoltaic potential for regional renewable energy policy. Comput. Environ. Urban Syst. 2010, 34, 345-357. [CrossRef]

37. Wan, C.; Zhao, J.; Song, Y.; Xu, Z.; Lin, J.; Hu, Z. Photovoltaic and solar power forecasting for smart grid energy management. CSEE Power Energy Syst. 2015, 1, 38-46. [CrossRef]

38. Kazem, H.A.; Yousif, J.H.; Chaichan, M.T. Modelling of Daily Solar Energy System Prediction using Support Vector Machine for Oman. Int. J. Appl. Eng. Res. 2016, 11, 10166-10172.

39. Cano, D.; Monget, J.M.; Albuisson, M.; Guillard, H.; Regas, N.; Wald, L. A method for the determination of the global solar radiation from meteorological satellite data. Sol. Energy 1986, 37, 31-39. [CrossRef]

40. Szabó, S.; Enyedi, P.; Horváth, M.; Kovács, Z.; Burai, P.; Csoknyai, T.; Szabó, G. Automated registration of potential locations for solar energy production with Light Detection And Ranging (LiDAR) and small format photogrammetry. J. Clean. Prod. 2016, 112, 3820-3829. [CrossRef]

41. Dolor, F.M. Phases of geothermal development in the Philippines. In Workshop for Decision Makers on Geothermal Projects and their Management; UNU-GTP: Reykjavík, Iceland, 2005; pp. 14-18.

42. Baniyounes, A.M. Renewable Energy Potential in Jordan. Int. J. Appl. Eng. Res. 2017, 12, 8323-8331.

43. Basaran, S.T.; Dogru, A.O.; Balcik, F.B.; Ulugtekin, N.N.; Goksel, C.; Sozen, S. Assessment of renewable energy potential and policy in Turkey-Toward the acquisition period in European Union. Environ. Sci. Policy 2015, 46, 82-94. [CrossRef]

44. Barbier, E. Geothermal energy technology and current status: An overview. Renew. Sustain. Energy Rev. 2002, 6, 3-65. [CrossRef]

45. Kana, J.D.; Djongyang, N.; Raïdandi, D.; Nouck, P.N.; Dadjé, A. A review of geophysical methods for geothermal exploration. Renew. Sustain. Energy Rev. 2015, 44, 87-95. [CrossRef] 
46. üyüközkan, G.; Feyzioğlu, O.; Nebol, E. Selection of the strategic alliance partner in logistics value chain. Int. J. Prod. Econ. 2008, 113, 148-158. [CrossRef]

47. Mongillo, M.; Cochrane, G.; Browne, P.; Deroin, J. Application of satellite imagery to explore and monitor geothermal systems. In Proceedings of the World Geothermal Congress, Florence, Italy, 18-31 May 1995; Volume 1, pp. 951-956.

48. Vasco, D.W.; Johnson, L.R.; Goldstein, N.E. Using surface displacement and strain observations to determine deformation at depth, with an application to Long Valley Caldera, California. J. Geophys. Res. 1988, 93, 3232. [CrossRef]

49. Mia, B.; Fujimitsu, Y. Mapping hydrothermal altered mineral deposits using Landsat 7 ETM+ image in and around Kuju volcano, Kyushu, Japan. J. Earth Syst. Sci 2012, 121, 1049-1057. [CrossRef]

50. Reath, K.A.; Ramsey, M.S. Exploration of geothermal systems using hyperspectral thermal infrared remote sensing. J. Volcanol. Geotherm. Res. 2013, 265, 27-38. [CrossRef]

51. Kruse, F.A. Mapping surface mineralogy using imaging spectrometry. Geomorphology 2012, 137, 41-56. [CrossRef]

52. Lin, H.; Xu, Q.; Zheng, Q. An overview on SAR measurements of sea surface wind. Prog. Nat. Sci. 2008, 18, 913-919. [CrossRef]

53. Calaudi, R.; Arena, F.; Badger, M.; Sempreviva, A.M. Offshore wind mapping mediterranean area using SAR. Energy Procedia 2013, 40, 38-47. [CrossRef]

54. Millward-Hopkins, J.T.; Tomlin, A.S.; Ma, L.; Ingham, D.B.; Pourkashanian, M. Assessing the potential of urban wind energy in a major UK city using an analytical model. Renew. Energy 2013, 60, 701-710. [CrossRef]

55. Lukač, N.; Štumberger, G.; Žalik, B. Wind resource assessment using airborne LiDAR data and smoothed particle hydrodynamics. Environ. Model. Softw. 2017, 95, 1-12. [CrossRef]

56. Avtar, R.; Suzuki, R.; Sawada, H. Natural Forest Biomass Estimation Based on Plantation Information Using PALSAR Data. PLoS ONE 2014, 9, e86121. [CrossRef] [PubMed]

57. Harrison, J.D. Tool for Preliminary Site-Suitability Analysis. Master's Thesis, University of Southern California, Los Angeles, CA, USA, August 2012.

58. Yi, C.S.; Lee, J.H.; Shim, M.P. Site location analysis for small hydropower using geo-spatial information system. Renew. Energy 2010, 35, 852-861. [CrossRef]

59. Jakubiec, J.A.; Reinhart, C.F. A method for predicting city-wide electricity gains from photovoltaic panels based on LiDAR and GIS data combined with hourly Daysim simulations. Solar Energy 2013, 93, 127-143. [CrossRef]

60. Catita, C.; Redweik, P.; Pereira, J.; Brito, M.C. Extending solar potential analysis in buildings to vertical facades. Comput. Geosci. 2014, 66, 1-12. [CrossRef]

61. Jacovides, C.P.; Tymvios, F.S.; Assimakopoulos, V.D.; Kaltsounides, N.A. Comparative study of various correlations in estimating hourly diffuse fraction of global solar radiation. Renew. Energy 2006, 31, 2492-2504. [CrossRef]

62. Norman, S.E. Solar Penetration Indicator; Patent and Trademark Office: Washington, DC, USA, 1959.

63. Hammer, A.; Heinemann, D.; Hoyer, C.; Toggweiler, P.; Brügger, U.; Reise, C.; Wiemken, E.; Beyer, H.G.; van Dijk, V.; Betcke, J. Surveillance of Photovoltaic Solar Energy Systems Using METEOSAT Derived Irradiances. In Proceedings of the EUMETSAT Meteorological Satellite Data Users' Conference, Bologna, Italy, 29 May-2 June 2000; pp. 613-618.

64. Environmental Systems Research Institute (esri). Boston Showcases Solar Power Potential with Web GIS. Available online: https://www.esri.com/news/arcnews/fall08articles/boston-showcases.html (accessed on 30 June 2019).

65. Coolbaugh, M.F.; Kratt, C.; Fallacaro, A.; Calvin, W.M.; Taranik, J.V. Detection of geothermal anomalies using Advanced Spaceborne Thermal Emission and Reflection Radiometer (ASTER) thermal infrared images at Bradys Hot Springs, Nevada, USA. Remote Sens. Environ. 2007, 106, 350-359. [CrossRef]

66. Gutiérrez, F.J.; Lemus, M.; Parada, M.A.; Benavente, O.M.; Aguilera, F.A. Contribution of ground surface altitude difference to thermal anomaly detection using satellite images: Application to volcanic/geothermal complexes in the Andes of Central Chile. J. Volcanol. Geotherm. Res. 2012, 237, 69-80. [CrossRef]

67. Vaughan, R.G.; Keszthelyi, L.P.; Davies, A.G.; Schneider, D.J.; Jaworowski, C.; Heasler, H. Exploring the limits of identifying sub-pixel thermal features using ASTER TIR data. J. Volcanol. Geotherm. Res. 2010, 189, 225-237. [CrossRef] 
68. Qin, Q.; Zhang, N.; Nan, P.; Chai, L. Geothermal area detection using Landsat ETM+ thermal infrared data and its mechanistic analysis-A case study in Tengchong, China. Int. J. Appl. Earth Obs. Geoinf. 2011, 13, 552-559. [CrossRef]

69. Haselwimmer, C.; Prakash, A.; Holdmann, G. Quantifying the heat flux and outflow rate of hot springs using airborne thermal imagery: Case study from Pilgrim Hot Springs, Alaska. Remote Sens. Environ. 2013, 136, 37-46. [CrossRef]

70. Watson, F.G.R.; Lockwood, R.E.; Newman, W.B.; Anderson, T.N.; Garrott, R.A. Development and comparison of Landsat radiometric and snowpack model inversion techniques for estimating geothermal heat flux. Remote Sens. Environ. 2008, 112, 471-481. [CrossRef]

71. Savage, S.L.; Lawrence, R.L.; Custer, S.G.; Jewett, J.T.; Powell, S.L.; Shaw, J.A. Review of alternative methods for estimating terrestrial emittance and geothermal heat flux for Yellowstone National Park using landsat imagery. GIScience Remote Sens. 2010, 47, 460-479. [CrossRef]

72. Mia, M.B.; Bromley, C.J.; Fujimitsu, Y. Monitoring heat flux using Landsat TM/ETM+ thermal infrared data-A case study at Karapiti ('Craters of the Moon') thermal area, New Zealand. J. Volcanol. Geotherm. Res. 2012, 235-236, 1-10. [CrossRef]

73. Boothroyd, I.K.G. Ecological characteristics and management of geothermal systems of the Taupo Volcanic Zone, New Zealand. Geothermics 2009, 38, 200-209. [CrossRef]

74. Nash, G.D.; Moore, J.N.; Sperry, T. Vegetal-spectral anomaly detection at the Cove Fort-Sulphurdale thermal anomaly, Utah, USA: Implications for use in geothermal exploration. Geothermics 2003, 32, 109-130. [CrossRef]

75. Fialko, Y.; Simons, M. Deformation and seismicity in the Coso geothermal area, Inyo County, California: Observations and modeling using satellite radar interferometry. J. Geophys. Res. Solid Earth 2000, 105, 21781-21793. [CrossRef]

76. Carnec, C.; Fabriol, H. Monitoring and modeling land subsidence at the Cerro Prieto Geothermal Field, Baja California, Mexico, using SAR interferometry. Geophys. Res. Lett. 1999, 26, 1211-1214. [CrossRef]

77. Sarychikhina, O.; Glowacka, E.; Mellors, R.; Vidal, F.S. Land subsidence in the Cerro Prieto Geothermal Field, Baja California, Mexico, from 1994 to 2005: An integrated analysis of DInSAR, leveling and geological data. J. Volcanol. Geotherm. Res. 2011, 204, 76-90. [CrossRef]

78. Lubitz, C.; Motagh, M.; Wetzel, H.U.; Kaufmann, H. Remarkable urban. uplift in staufen im Breisgau, Germany: Observations from TerraSAR-X InSAR and leveling from 2008 to 2011. Remote Sens. 2013, 5, 3082-3100. [CrossRef]

79. Sass, I.; Burbaum, U. Damage to the historic town of Staufen (Germany) caused by geothermal drillings through anhydrite-bearing formations. Acta Carsologica 2010, 39. [CrossRef]

80. García-Martín, A.; de la Riva, J.; Pérez-Cabello, F.; Montorio, R. Using remote sensing to estimate a renewable resource: Forest residual biomass. In Remote Sensing of Biomass-Principles and Applications; IntechOpen: London, UK, 2012.

81. Lefsky, M.A.; Cohen, W.B.; Parker, G.G.; Harding, D.J. Lidar Remote Sensing for Ecosystem Studies. BioScience 2014, 52, 19-30. [CrossRef]

(C) 2019 by the authors. Licensee MDPI, Basel, Switzerland. This article is an open access article distributed under the terms and conditions of the Creative Commons Attribution (CC BY) license (http://creativecommons.org/licenses/by/4.0/). 